
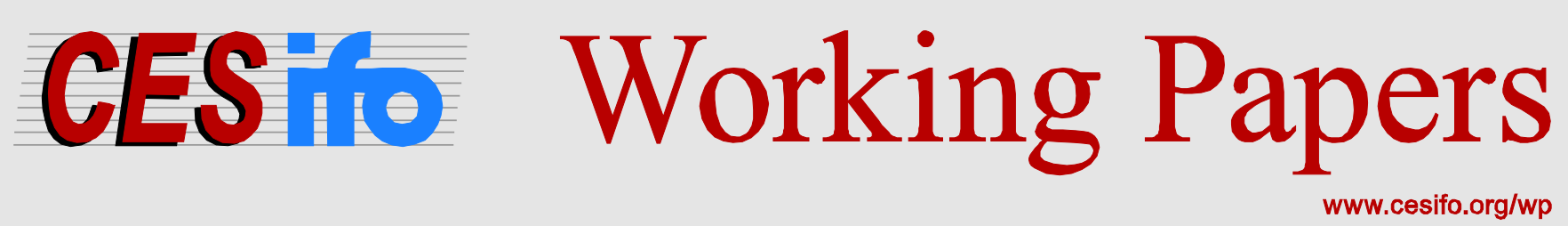

\title{
Socio-Economic Heterogeneity and Electoral Turnout: An Aggregate Analysis with Precinct-Level Data
}

\author{
Giorgio Bellettini \\ Carlotta Berti Ceroni \\ Chiara Monfardini
}

CESIFO WORKING PAPER NO. 4999

CATEgory 2: Public CHOICE

SEPTEMBER 2014
An electronic version of the paper may be downloaded
- from the SSRN website:
- from the RePEc website:
- from the CESifo website:
WwW.SSRN.com
www.RePEc.org
www.CESifo-group.org/wp

\section{CESifo}




\title{
Socio-Economic Heterogeneity and Electoral Turnout: An Aggregate Analysis with Precinct-Level Data
}

\begin{abstract}
In this paper we perform an empirical analysis to investigate the impact of socio-economic heterogeneity on electoral turnout. We exploit a unique dataset on local elections in an Italian municipality, which merges information on socio-economic characteristics of about 370.000 individuals with turnout data at the precinct level in 2004 and 2009. Controlling for unobserved precinct-specific fixed effects, we find that electoral turnout is not affected by income inequality. We also document a negative effect on electoral participation of the share of immigrants, population density, and the share of singles. These results suggest that increased ethnic heterogeneity and reduced social pressure tend to depress turnout.
\end{abstract}

JEL-Code: D720.

Keywords: income inequality, electoral turnout, heterogeneity.

\author{
Giorgio Bellettini \\ University of Bologna / Italy \\ giorgio.bellettini@unibo.it
}

\author{
Carlotta Berti Ceroni \\ University of Bologna / Italy \\ bceroni@economia.unibo.it
}

\author{
Chiara Monfardini \\ University of Bologna / Italy \\ chiara.monfardini@unibo.it
}

\section{September 2014}

We would like to thank the Statistical Office of the Comune di Bologna, and in particular Gianluigi Bovini, for data provision. We benefited from comments by participants to the 13th Journées Louis-André Gerard-Varet and especially by our discussant Anna Lo Prete. We are grateful to Enrico Cantoni for fruitful discussions and Antonio Dalla Zuanna for excellent research assistantship. 


\section{Introduction}

Well-documented historical trends show that, in the last decades, most democratic countries experienced a rise in economic inequality and a drop in political participation (see for instance the figures in Horn 2011, pp. 11-13). According to a recent publication of the International Institute for Democracy and Electoral Assistance (IDEA), "Electoral participation is in general falling, at least as measured by voter turnout. Rising levels of public apathy or cynicism are of growing concern in both newer and older democracies, and are a particular focus of concern in Western Europe" (IDEA 2006, p. 5).

While the effects of individual and institutional characteristics on political participation (in particular, electoral turnout) have been extensively investigated, especially among political scientists (for a recent survey, see Blais 2006), there is little theoretical analysis and empirical evidence of the link between economic inequality and political participation. As the APSA Task Force on Inequality and American Democracy puts it, "there is little evidence of a direct effect of rising economic inequality on widening political disparities, but we need to confirm or challenge this impression with more analysis of the complex political associations with rising inequality. "(APSA 2004, p. 662).

If we consider inequality as one of the many possible dimensions of socio-economic heterogeneity, a more general question arises of whether turnout should be higher or lower in heterogeneous communities. Exploring this issue, the existing literature has focused on several dimensions of heterogeneity - such as ethnic or racial composition of the neighborhood - but has neglected the role of economic heterogeneity, as data on income inequality are typically not available at the neighborhood level.

Motivated by the aforementioned arguments, in this paper we study the effect of socioeconomic heterogeneity on electoral turnout. In particular, we add to the empirical literature on the link between income inequality, ethnic heterogeneity and aggregate turnout by exploiting a unique panel dataset for the 2004 and 2009 local elections in Bologna, an Italian municipality of about 370.000 inhabitants in the Center-North of Italy.

Two are the most important and distinctive features of our dataset which, to the best of our knowledge, are unique in the literature. First, we rely on data that come exclusively from official sources and cover the entire municipality's population. This distinguishes our paper from those that use survey data. Second, all variables of interest are measured and computed at the precinct level, that is, at the smallest unit for which electoral outcomes are officially reported. This latter feature allows us to aggregate individual information yet working with a large number of observations within the municipality's boundaries. It 
is worth emphasizing that we could compute measures of income inequality at the precinct level due to the availability of information on individual incomes, taken from official income tax files.

Our main empirical finding is twofold. Exploiting substantial variability across precincts and across the two elections, on the one hand we show that the negative association between income inequality and voter turnout uncovered at the precinct level is driven by an omitted variable bias. On the other hand, we find evidence of a negative impact of ethnic heterogeneity (measured by the share of African and Asian immigrants over the precinct's population) on voter turnout, controlling for economic inequality. These results are robust to the use of alternative inequality measures such as the median-to-mean ratio, the Gini index, and the ratio of the 80th to 20th percentiles. We also document a positive relationship between the level of social pressure (captured by the percentage of singles and population density) and voter turnout. As we discuss in the paper, these empirical results can be rationalized within some long-established theories that assess the possible mechanisms through which socio-economic heterogeneity and social pressure affect political participation.

The remaining of the paper is organized as follows. Section 2 provides a review of the theoretical and empirical literature on heterogeneity and electoral participation. Section 3 describes the institutional and legal framework of Italian local elections. Section 4 illustrates the main features of the dataset and discusses the empirical strategy, while Section 5 presents the empirical results. Section 6 concludes.

\section{A review of the literature}

From a theoretical point of view, the effect of income inequality on electoral participation is unclear. According to a well-established perspective in political science, the so-called "power theory" (see Schattschneider, 1960 and Goodin and Dryzek, 1980), inequality should have a negative impact on turnout as higher concentration of economic power would lead to the removal of pro-poor issues in the political agenda and reduce incentives for participation of the poor and, to a lower extent, of the rich.

On the contrary, according to the "conflict theory" (see Meltzer and Richards, 1981), higher economic inequality leads to more conflictive politics (e.g. higher redistribution) and stimulates more interest and participation among both the poor and the rich.

Notwithstanding different underlying mechanisms and predictions, the above-mentioned theories share the view that inequality directly affects individual incentives to participa- 
tion. However, the observed effect of inequality on turnout, if any, may simply be a consequence of individual behavior responding to resources, as noted by Solt $(2008,2010)$. According to the "resource theory", participation tends to be higher for high-income citizens and higher inequality, which implies fewer resources for the poor and more for the rich (for any given average income), may have an ambiguous effect on turnout, depending on whether the positive effect of higher income on participation of the rich outweighs the negative effect on the poor.

Although the link between income inequality and electoral turnout has been the subject of a voluminous empirical literature, no conclusive evidence has been yet provided and the issue remains highly debated, as we mentioned in the previous Section.

Several empirical analyses put together survey data on individual turnout, income and individual characteristics, and information on income inequality and other contextual variables at the sub-national or cross-country level. Overall, this strand of evidence seems to indicate that income inequality is negatively associated with the likelihood of voting (Anderson and Beramendi, 2008; Horn, 2011; Jaime-Castillo, 2009; Nguyen and Garand, 2007; Seeber and Steinbrecher, 2011; Solt, 2008, 2010) and that the effect is stronger for the poor, supporting power theory (see, in particular, Anderson and Beramendi, 2008; Solt, 2008, 2010). However, other studies find the opposite result, that is turnout increases with inequality, especially among the poor (see, for example, Brady, 2003), or find no evidence of a differential effect of inequality on turnout among the rich and the poor (Horn, 2011; Wichowski, 2010).

Other studies rely on aggregate data. Again, results are inconclusive. Although some papers provide evidence of a negative association between income inequality and turnout using data at the country (Lister, 2007) or regional level (Mahler, 2002), in a recent work on national legislative elections in democratic countries Stockemer and Scruggs (2012) find no relationship and suggest that the negative association estimated in previous studies (including those using individual-level survey data observed through time) may be spurious and driven by the omission of a time trend. Indeed, as discussed in the Introduction, electoral turnout and income inequality have followed opposite trends over the years and it is important to control for time effects when studying the relationship between these variables exploiting also their time variation.

From a broader perspective, which is closer to the spirit of our contribution, economic inequality can be seen as one dimension of social heterogeneity, together with racial or ethnic diversity. Heterogeneity may have a negative effect on turnout by reducing social cohesion, interpersonal trust and social pressure towards participation (Alesina and La 
Ferrara, 2000; Putnam, 2007). In his extensive review of aggregate-level empirical evidence on the determinants of turnout, Geys (2006) concludes that population heterogeneity and turnout are weakly related. However, in a recent paper using prefecture-level panel data on national legislative elections in Japan, Yamamura (2011) finds that voter turnout is associated with social cohesion and fragmentation and that income inequality has a negative effect.

Recent contributions focus on the impact of neighborhood characteristics. Barber and Imai (2014), exploiting a large data set on individual registration records in California, Florida and North Carolina, show that increases in the out-group neighborhood proportion depress the probability of turnout, where the out-group is defined in terms of race or political partisanship. Estrada-Correa and Johnson (2012) provide evidence that foreclosure rates and percentage of Latinos depressed aggregate and individual turnout in California zip-codes at 2008 Presidential elections. Kaniowski and Mueller (2006) argue that population size and linguistic heterogeneity negatively affected voter turnout in Norwegian school language referenda. Within this literature, some studies rely on information at the precinct level (see Fieldhouse and Cutts, 2008; Kofheld and Sprague, 2002; Pellissero, 2000).

Note however that the existing literature on neighborhood characteristics could not address the role of economic heterogeneity on political participation. In fact, individuallevel information on income of neighborhood resident population is typically not available and indicators of income inequality cannot be calculated. To the best of our knowledge, our study is the only one in which income inequality is measured at the neighborhood (i.e. precinct) level. As we will discuss later, this represents a remarkable advantage for the identification of a possible causal effect of income inequality on turnout and for the interpretation of empirical results. Moreover, it allows us to disentangle the effect of different dimensions of heterogeneity, by considering income inequality together with ethnic heterogeneity as possible determinants of political participation in the community.

\section{The institutional framework}

In this paper we focus on two consecutive municipal elections held in 2004 and 2009 in Bologna, a large municipality in the Center-North of Italy.

According to the Italian Law, the mayor and the municipality council are appointed through local elections which take place, as a general rule, every five years. The mayor is elected directly. Each candidate must be supported by a list or a coalition of lists 
of residents in the municipality, Italian or EU citizens, running for a seat in the council. Voters, if they wish, can cast separate preferences for mayor and council ("voto disgiunto"). In municipalities with more than 15.000 inhabitants, such as Bologna, the mayor is elected through a two-round majority system: if no candidate reaches the absolute majority of valid votes in the first round, the two most voted candidates run for a second round ("ballottaggio") and the one who gets the relative majority is elected.

In the case of Bologna, Sergio Cofferati, a former union leader, was elected in the first round in 2004. The turnout rate was $81.81 \%$ and Cofferati gained 55,92\% of the valid votes. In 2009, Cofferati did not run for re-election in 2009, although he might have done so (a two-term limit applies according to the above-mentioned law) and the elected mayor was Flavio Delbono, a former University professor, who gained $49.40 \%$ of the votes in the first round and won the elections in the second round with $60.77 \%$ of the votes. In the first and second round, the turnout rate was $76.39 \%$ and $62.20 \%$ respectively.

Since the end of the Second World War, Bologna has had a long tradition of left-wing administrations and the two elections we consider here make no exception. In both years, the elected mayor was supported by center-left coalitions. This observation will play an important role in our identification strategy, as discussed in the following Section. It is also worthwhile to note that the previous election, held in 1999, was peculiar in Bologna's electoral history, as a center-right mayor, Giorgio Guazzaloca, secured victory for the first time. The desire to restore a left-wing government may have stimulated participation in 2004. This observation, together with the fact that the 2004 election has been the first one to be held under the current electoral system, and with the generalized downward trend in turnout (see the descriptive statistics presented below), makes the introduction of a time trend in the specification particularly advisable in our context.

The municipal electoral register in Bologna entails 436 different precincts which include geographically close areas. Eligible voters (Italian and EU citizens above 18 years of age who are residents in the municipality) are registered in a precinct depending on their residence address (registration is automatic for Italian citizens).

\section{Data description and empirical strategy}

Data on our key variables (electoral turnout, income inequality and ethnic heterogeneity) come from a unique source of information, i.e. the Municipal Statistical Office in Bologna.

We were provided with the actual number of registered voters and the number of 
voters casting a ballot in each precinct for the 2004 and 2009 administrative elections. ${ }^{1}$ The precinct's voter turnout was then merged with socio-economic individual data for the population residing within the precinct boundary, coming from income tax files and civil registers. Income tax files years correspond to the election years, while information from civil registers was drawn at the available calendar time closest to the election date. ${ }^{2}$

Building on individual data, different socio-economic variables - such as average income, population size and density, percentage of homeowners, percentage of singles, mean age and gender composition - were computed at the precinct level. Most importantly for our purposes, we were provided with a set of income inequality indicators - such as the median-to-mean ratio, the Gini index, the ratio of the 80th to 20 th percentile (p80/p20) computed from individual income tax files, and the percentage of foreign immigrants from different regions (Africa, Asia, East Europe, others) who reside in the precinct, calculated from individual register data, which we take as a measure of ethnic heterogeneity.

Table 1a in the Appendix presents descriptive statistics by year and in the pooled sample. The number of precincts observed in both elections was 434, excluding electoral sites in hospitals, so that we built a panel dataset with $n=434, t=2004,2009$. Variables' names are self explanatory. With the exception of turnout, whose denominator is given by the number of registered voters, all other percent variables refer to the whole population residing in the precinct (population). Population density is the number of residents by square kilometer. In order to capture real income changes across the two years, the 2009 income was deflated using inflation indexes reported by the Italian Statistical Office (ISTAT). Note that all variables exhibit both cross sectional and time variation that will be crucial to our empirical strategy. More specifically, Table 1b reports summary statistics of the differenced variables across the two years. It documents the existence of substantial time variation within precincts for the main variables of interest which supports the fixedeffect strategy that we will exploit for identification.

The unique features of our dataset, that allow to solve several identification problems of the existing literature (which we discussed in Section 2), are worthwhile detailing here. First, by focusing on a single municipality and on administrative local elections, we can safely rely on a rather parsimonious specification, as several controls typically included in aggregate-level studies of the determinants of electoral turnout (see Geys, 2006), such as institutional characteristics (electoral systems, compulsory voting, registration re-

\footnotetext{
${ }^{1}$ For the 2009 election we considered only the first-round vote.

${ }^{2}$ This date was May 31 for both 2004 and 2009 elections, which took place on June 12-13 and June 6-7 respectively.
} 
quirements) and political factors (political fragmentation, closeness of elections, campaign expenditures) are not relevant in our context, as they are common across our units of observation.

Second, existing aggregate-level studies on turnout and income inequality typically rely on cross-sectional data from different countries and estimation results may be plagued by omitted variable bias. ${ }^{3}$ Studies on ethnic heterogeneity and turnout - which are based on a single period of observation and a limited set of observed explanatory variables taken from the Census - are also likely to be prone to omitted variable bias. ${ }^{4}$ On the contrary, our homogeneous environment strongly reduces the possibility of omitted variable bias, which we further tackle by exploiting the panel dimension of the data, so as to eliminate the influence of unobservable time-invariant factors at the precinct level.

Third, the negative association between turnout and inequality may be the outcome of decreased participation which spurs higher inequality. As argued by Mueller and Stratmann (2003), lower aggregate turnout could be associated to decreasing participation among the poor which implies less redistributive policies and increased income inequality. More generally, a change in turnout may influence the political orientation of the elected government and determine policy changes which in turn affect income inequality. This should not be an issue in our context, in which the left-wing orientation of municipal political institutions was basically unchanged over the period considered.

Fourth, by investigating the relationship between turnout and income inequality at the precinct level, we can isolate the effect of heterogeneity on political participation. In fact, as political competition and policy platforms are independent of changes in inequality at the precinct level, we can exclude that power and conflict theories play a role in our

\footnotetext{
${ }^{3}$ An exception is Yamamura (2011) who uses prefecture-level longitudinal data from Japan. Yet, his specification is questionable, as some potentially relevant explanatory variables - such as the closeness of elections - and time dummies are not included. Moreover, at the prefecture level, there may be several unobserved time-varying factors that influence turnout and are correlated with regressors. Consider, for example, weather conditions on elections dates, that may undermine participation and be unobservable by the researcher. The probability of adverse weather depends on climatic factors that vary over space and may be correlated with some right-hand side variable such as, for example, income. Notice also that, according to the well known Engerman and Sokoloff's (2000) hypothesis, differences in income inequality may also be related to varying climatic and geographic conditions. Clearly, this issue is not relevant in our context, as weather conditions on election dates are unchanged across precincts. Similar arguments hold for many other factors that may be influential in cross-country, cross-region or cross-prefecture analysis but are irrelevant in our context.

${ }^{4} \mathrm{An}$ exception is Barber and Imai (2014) who use difference-in-difference estimation and panel data on individual turnout.
} 
context (see our discussion in Section 2).

Finally, the joint availability of measures of income inequality and ethnic heterogeneity at the precinct level allows us to disentangle the effects of different dimensions of heterogeneity on political participation. Previous studies on the effect of neighborhood composition could not control for economic inequality, for which data are typically not available at this tiny level of observation, making the interpretation of results questionable. As ethnic minorities generally belong to the poor segment of the population and an inflow of foreign immigrants may imply an increase in income inequality at the neighborhood level, one may mistakenly associate an effect on political participation to ethnic heterogeneity while it actually goes through economic heterogeneity. Similar considerations apply when the association between inequality and turnout is investigated without including alternative measures of social heterogeneity.

Based on the previous discussion, we will identify the effect of income inequality and ethnic heterogeneity through the following linear model:

$$
\text { turnout }_{i t}=\beta_{1} \text { ineq }_{i t}+\beta_{2} \text { ethnic_het }_{i t}+\beta_{3} X_{i t}+\eta_{t}+\alpha_{i}+\varepsilon_{i t}
$$

where $i$ denotes the precinct, $t$ denotes the year of elections (2004 or 2009), $\eta_{t}$ is a time effect, $\alpha_{i}$ is the precinct time-invariant unobserved heterogeneity, ineq $q_{i t}$ is income inequality, ethnic_het ${ }_{i t}$ is the percentage of foreign people and $X_{i t}$ is a vector of controls.

As discussed above, several factors that have been previously found to affect aggregate turnout play no role in our context so that our specification is deliberately parsimonious. To isolate the effect on turnout of a mean-preserving spread of the income distribution we always include average income among controls. Depending on specifications, we also include variables that are usually associated to turnout, such as measures of social pressure (percentage of individuals living alone, population density), stability in the community (homeownership), and demographic characteristics (average age of resident people, percentage of females). The time effect controls for the general downward trend in turnout and for the possibility that the 2004 election had peculiar characteristics, as discussed in Section 3 .

We estimate our coefficients of interest by means of pooled OLS regressions with different set of controls and by fixed effects. The latter estimation approach eliminates the potential bias arising from precinct-level unobservables $\alpha_{i}$ being correlated with income inequality or other observable regressors. In our case, unobserved heterogeneity accounts for different social and cultural attitudes characterizing people living in different precincts, 
who are exposed to different local initiatives, both public and private, shaping the sense of local community.

\section{$5 \quad$ Estimation Results}

We start our empirical analysis by investigating the effect of income inequality on electoral participation. Our goal here is to overcome the ambiguous conclusions of previous research about the existence and the extent of such effect, exploiting the peculiar advantages of our case study illustrated above. Table 2 displays descriptive pooled OLS regressions of turnout on three different income inequality indexes, controlling for the average income and the election year. Higher income inequality turns out to be always significantly associated with a lower turnout rate, for all inequality indexes (Median-to-Mean Ratio, Gini Index, $p 80 / p 20) .^{5}$

This negative association between income inequality and turnout is in line with the argument that higher heterogeneity - of which income inequality is one dimension - discourages electoral participation by reducing social cohesion, interpersonal trust among community's residents, and eventually social pressure towards political participation. However, as we will show in the next steps of our estimation exercise, this negative effect of income inequality on turnout is driven by an omitted variable bias and is not robust to the inclusion of observable time-varying precinct characteristics and to time constant unobserved heterogeneity.

In Tables 3a, 3b, and 3c we take a closer look to OLS regressions where, along with the three inequality indexes, we include the percentage of all foreign people (first column of the three tables), and a set of other observable contextual variables (columns 2 to 5 of the three tables). The magnitude of the inequality coefficient is gradually reduced once we condition to an increasing set of other determinants of turnout, as it can be observed comparing the estimated OLS coefficients of Median-to-Mean Ratio (Table 3a), Gini (Table 3b), p80/p20 (Table 3c) across the different columns.

This general pattern is corroborated by the fixed-effect estimation results reported in Table $4 \mathrm{a}, 4 \mathrm{~b}$ and $4 \mathrm{c}$, where the income inequality effect is also purged from the bias induced by precinct unobserved heterogeneity. The fixed effects Median-to-Mean Ratio coefficient is found to be not statistically different from zero as soon as the precinct's population composition in terms of foreign and single people is taken into account (Table

\footnotetext{
${ }^{5}$ Notice that an increase in the Median-to-Mean Ratio (for given mean income) corresponds to lower inequality. On the contrary, higher Gini or p80/p20 correspond to an increase in income inequality.
} 
4a, second column). An even stronger result is found on the Gini and on the ratio p80/p20 fixed effects coefficients, which appear to be statistically equal to zero across all considered specifications (Tables $4 \mathrm{~b}$ and $4 \mathrm{c}$ ). The overall conclusion that we derive from this evidence is against income inequality playing a role in determining turnout at the precinct level. Economic heterogeneity seems not to affect social cohesion and pressure towards participation within the precinct.

We now turn to ethnic heterogeneity, which we measure with the percentage of foreigners who live in the precinct. As shown in Tables 3a-c and 4a-c, this measure displays a negative and statistically significant coefficient in the OLS and the FE estimation, across most specifications and for any chosen index of income inequality.

The only exception to this trend is represented by OLS regressions which include the percentage of homeowners (last column of Tables 3a, 3b, and 4c). In this case, the substantial negative correlation between the percentage of foreign people and that of homeowners across precincts makes it difficult to disentangle the effect of ethnic heterogeneity from that of population stability, captured by the percentage of people who own their houses. However, when we turn to our preferred FE specification, we observe a negative and significant coefficient of ethnic heterogeneity which is robust across all regressions (Tables 4a, $4 \mathrm{~b}$, and $4 \mathrm{c}$ ). Here, identification is improved due to different time variation patterns exhibited by the share of foreigners and that of homeowners, which imply a lower correlation between their time difference.

In order to capture the effect of ethnic heterogeneity on electoral behavior more precisely, we computed a measure that takes into account the degree of foreigners' ethnic distance from Italian natives. Specifically, we selected groups that are likely to be perceived by eligible voters as the most distant due to their somatic traits and computed the share of African and Asian immigrants over the precinct's population. Both OLS and fixed effects coefficients remain negative and mostly significant across the inclusion of different controls, with FE estimates ranging from -0.20 (second column) to -0.15 (last column). We take the last column of Table $5 \mathrm{a}$ as our preferred specification, since it controls for unobserved fixed effects and for the largest number of observable regressors (including income inequality, measured by the Gini index). The FE ethnic heterogeneity coefficient implies that a ceteris paribus one percentage point increase in the African and Asian population composition reduces the precinct's turnout of 0.15 percentage points (its counterpart obtained with the previous definition of ethnic heterogeneity was a negative 0.12, last column of Table $4 \mathrm{~b}$ ). To gauge the relevance of this effect, consider that a 2 percentage point increase in the share of migrants from Africa and Asia in the precinct 
(which is about the sample average variation observed between 2004 and 2009, see Table $1 \mathrm{~b})$ is estimated to cause a 0.3 percentage point decrease in electoral participation. In our last set of estimation results (Table 5b) we let the precinct's turnout depend on the percentage of foreigners coming from Eastern Europe. Immigrants of this group are not easily perceived as foreigners, given their ethnic similarity to Italian natives. The fact that FE coefficients are diminished in magnitude and lose significance in our preferred specification (last column of Table 5b) testifies that the degree - or the intensity - of ethnic heterogeneity plays an important role in shaping electoral behavior of registered voters, who are mostly Italian in our context.

Within our preferred specification (last column of Table 5a) we also find clear evidence of the relevance of the "social pressure" explanations for electoral participation. Population density is usually included in turnout studies expecting that in densely populated neighborhoods politics are more individualistic, and social pressure on potential voters to cast their ballot is lower. While existing evidence from aggregate studies fails to support this argument (see Geys, 2006), we find a negative and sizable effect of population density on turnout. ${ }^{6}$ A one unit increase in the number of resident people per square kilometer reduces precinct turnout of about 0.36 percentage points. The view that social pressure increases turnout is also supported by the significant and negative coefficient of the variable measuring the percentage of people aged less than 64 and living alone (\% singles aged $<64$ ). A unit increase in the percentage of these single people, implying a lower level of social pressure in the community, is found to bring about a 0.17 percentage points decrease in turnout. This result is interesting given the current demographic trend on family formation in the Italian society, with an increasing share of people choosing to live alone.

Finally, we find (marginally significant) positive coefficients for the gender composition and average age variables. The interpretation of these coefficients as contextual effects on electoral participation at the individual level is, however, problematic. For example, we are not able to assess whether the positive effect of gender is due to the fact that females tend to vote more than males or that a higher presence of females in the local community increases cohesion and interpersonal bonds. ${ }^{7}$ To disentangle contextual from individual

\footnotetext{
${ }^{6}$ Some studies provide evidence that electoral participation is lower in large communities, where social pressure is weaker. For instance, Funk (2010) shows that the introduction of postal voting - which has ambiguous effect on turnout as it reduces voting costs but also the social pressure to vote, as the voting act is no longer observable - had stronger negative effect on electoral participation in smaller communities in Swiss federal party elections, consistently with the idea that social incentives play a role in voting decisions.

${ }^{7}$ This is an example of the well-known ecological fallacy issue, that is, the problem of inferring individual effects from aggregate-level data in the presence of contextual effects on individual behavior.
} 
effects, individual-level data on electoral participation and socio-economic status must be combined with relevant aggregate-level characteristics of the precinct. This is the ambitious goal of our next research agenda.

\section{Conclusions}

In this paper we exploit the access to data on individual incomes and precinct's electoral turnout for two local elections on a medium-size Italian municipality to provide a valuable contribution to the empirical literature on the link between socio-economic heterogeneity and political participation.

Our main result on the effect of income inequality on electoral turnout contrasts with several previous findings. Controlling for observable time-varying precinct's characteristics and time-constant unobserved heterogeneity, we find that income inequality has no statistically significant effect on aggregate turnout.

While income inequality seems not to play a role, the share of immigrants at the precinct level (a measure of ethnic heterogeneity) turns out to be negatively associated with turnout. A negative association is also detected between population density and turnout, which we interpret as evidence of the importance of social pressure for electoral participation.

The complex interrelationships between income and political inequality need to be carefully analyzed and more research is urgent to assess the effect of increasing income inequality on political behavior and public policy. We believe that our empirical analysis can help to shed light on these crucial issues and, more generally, on the impact of socioeconomic heterogeneity on political participation.

\section{References}

[1] Alesina, A. and La Ferrara, E. (2000). Participation in Heterogeneous Communities, The Quarterly Journal of Economics, 115: 847-904.

[2] APSA Task Force Report (2004). American Democracy in an Age of Rising Inequality, Perspectives on Politics, 2(4): 651-666.

[3] Anderson, C. J. and Beramendi, P., (2008). Income inequality and democratic representation. In Pablo Beramendi \& Christopher J. Anderson (Eds.),Democracy, in- 
equality, and representation: A comparative perspective (387-416). New York, NY: Russell Sage.

[4] Barber, M. and Imai, K. (2014). Estimating Neighborhood Effects on Turnout from Geocoded Voter Registration Records, Princeton University, mimeo.

[5] Blais, A. (2006). What Affects Voter Turnout, Annual Review of Political Science, 9: 111-125.

[6] Brady, H.E. (2004). An Analytical Perspective on Participatory Inequality and Income Inequality, in K. M. Neckerman (ed.), Social Inequality. New York: Russell Sage Foundation, 667-702.(2003). An Analytical Perspective on Participatory Inequality and Income Inequality, mimeo.

[7] Estrada-Correa, V. and Johnson M. (2012). Foreclosure Depresses Voter Turnout: Neighborhood Disruption and the 2008 Presidential Election in California, Social Science Quarterly, 93 (3), 559-576.

[8] Fieldhouse E. and Cutts D. (2008). Diversity, density and turnout: The effect of neighbourhood ethno-religious composition on voter turnout in Britain, Political Geography, 27, 530-548.

[9] Funk, P. (2010). Social Incentives and Voter Turnout: Evidence from the Swiss Mail Ballot System, Journal of the European Economic Association, 8(5): 1077-1103.

[10] Geys B. (2006). Explaining Voter Turnout: a Review of Aggregate-Level Research, Electoral Studies, 25(4): 637-663.

[11] Goodin, R., and Dryzek, J.(1980). Rational Participation: The Politics of Relative Power, British Journal of Political Science 10(3): 273-92.

[12] Horn, D. (2011). Income Inequality and Voter Turnout, Gini Discussion Paper no. 16.

[13] International Institute for Democracy and Electoral Assistance (2006). Engaging the Electorate: Initiatives to Promote Voter Turnout From Around the World.

[14] Jaime-Castillo, A.M. (2009). Economic Inequality and Electoral Participation. A Cross-Country Evaluation, mimeo.

[15] Kaniowski, S., and Mueller, D.C. (2006). Community Size, Heterogeneity and Voter Turnouts, Public Choice, 129: 399-415. 
[16] Kohfeld, C.W., and Sprague, J. (2002). Race, Space, and Turnout, Political Geography, 21: 175-193.

[17] Lister, M. (2007). Institutions, Inequality and Social Norms: Explaining Variations in Participation, British Jounral of Politics and International Relations, 9: 20-35.

[18] Luttmer, E.F.P., and Shue, K. (2009). Who Misvotes? The Effect of Differential Cognition Costs on Election Outcomes, American Economic Journal: Economic Policy, 1: $229-257$.

[19] Mahler, V.A. (2002). Exploring the Subnational Dimension of Income Inequality: An Analysis of the Relationship Between Inequality and Electoral Turnout in the Developed Countries, International Studies Quarterly, 46: 117-142.

[20] Meltzer, A. H., and Richard, S.F. (1981). A Rational Theory of the Size of Government, Journal of Political Economy, 89(5): 914-27.

[21] Mueller, D.C., and Stratmann, T. (2003). The Economic Effects of Democratic Participation, Journal of Public Economics, 87 (9-10): 2129-2155(2002).

[22] Nguyen, N.K., and Garand, J.C. (2007). The Effects of Income Inequality on Political Attitudes and Behavior, mimeo.

[23] Pelissero, J.P., Krebs, T.B., and Jenkins, S. (2000). Asian Americans, Political Organizations, and Participation in Chicago Electoral Precincts, Urban Affairs Review, 35: $750-769$.

[24] Putnam, R. (2007). E Pluribus Unum: Diversity and Community in the Twenty-first Century, Scandinavian Political Studies, 30(2), 137-174.

[25] Schattschneider, E.E. (1960). The Semisovereign People: A Realist's View of Democracy in America. New York: Holt, Reinhart and Wiston.

[26] Seeber, G.U.H., and Steinbrecher, M. (2011). Inequality and Turnout in Europe, mimeo.

[27] Solt, F. (2008). Economic Inequality and Democratic Political Engagement, American Journal of Political Science, 52(1): 48-60.

[28] Solt, F. (2010). Does Economic Inequality Depress Electoral Participation? Testing the Schattschneider Hypothesis, Polititical Behavior, 32: 285-301. 
[29] Stockemer, D., and Scruggs, L. (2012). Income Inequality, Development and Electoral Turnout. New Evidence on a Burgeoning Debate, Electoral Studies, 31(4): 764-773.

[30] Sokoloff, K.L., and Engerman, S.L. (2000). History Lessons. Institutions, Factor Endowments, and Paths of Development in the New World, Journal of Economic Perspectives, 14(3): 217-232.

[31] Wichowski, A. (2010). Who Turns Out to Vote: Resources, Power, and Competition in Elections, mimeo.

[32] Yamamura, E. (2011). Effects of Social Norms and Fractionalization on Voting Behaviour in Japan, Applied Economics, 43(11): 1385-1398. 


\section{Appendix}

Table 1a. Summary statistics

\begin{tabular}{|c|c|c|c|c|c|c|}
\hline & \multicolumn{2}{|c|}{2004} & \multicolumn{2}{|c|}{2009} & \multicolumn{2}{|c|}{ 2004-2009 pooled } \\
\hline Variable & Mean & Std. Dev. & Mean & Std. Dev. & Mean & Std. Dev. \\
\hline$\%$ Turnout & 81.49 & 5.40 & 76.25 & 5.81 & 78.87 & 6.19 \\
\hline Registered voters & 733.44 & 57.18 & 698.78 & 69.92 & 716.11 & 66.15 \\
\hline \multicolumn{7}{|l|}{ Income distribution indicators } \\
\hline Mean Income (Thousand Euros) & 25.34 & 7.86 & 24.88 & 7.87 & 25.11 & 7.87 \\
\hline Median to Mean Income Ratio & 0.81 & 0.12 & 0.82 & 0.12 & 0.82 & 0.12 \\
\hline Gini Index & 0.44 & 0.08 & 0.45 & 0.08 & 0.45 & 0.08 \\
\hline Ratio of percentiles: $\mathrm{p} 80 / \mathrm{p} 20$ & 4.04 & 1.46 & 4.44 & 1.92 & 4.24 & 1.71 \\
\hline 20th percentile, p20 & 8.69 & 1.49 & 8.03 & 1.64 & 8.36 & 1.60 \\
\hline$\%$ foreign people (all) & 5.79 & 3.29 & 10.49 & 4.75 & 8.14 & 4.71 \\
\hline$\%$ immigrants from Asia and Africa & 3.49 & 2.67 & 5.46 & 3.52 & 4.48 & 3.27 \\
\hline$\%$ immigrants from East Europe & 1.61 & 1.13 & 3.95 & 1.90 & 2.78 & 1.95 \\
\hline$\%$ single aged $<64$ & 14.06 & 6.22 & 17.12 & 6.95 & 15.59 & 6.76 \\
\hline population density^ & 11.18 & 7.16 & 11.14 & 7.13 & 11.16 & 7.14 \\
\hline$\%$ female & 47.76 & 2.79 & 47.25 & 2.70 & 47.51 & 2.75 \\
\hline average age & 47.29 & 3.21 & 47.20 & 3.17 & 47.24 & 3.19 \\
\hline$\%$ homeowners & 55.93 & 13.36 & 52.35 & 11.86 & 54.14 & 12.75 \\
\hline population & 859.70 & 87.36 & 860.50 & 103.98 & 860.10 & 95.98 \\
\hline Number of obs. (precincts) & 434 & & 434 & & 868 & \\
\hline population in thousands $/ \mathrm{km}^{2}$ & & & & & & \\
\hline
\end{tabular}


Table 1b. Variation across the two years

\begin{tabular}{|c|c|c|c|c|}
\hline Differenced variable (2009-2004) & Mean & Std. Dev. & Min & $\operatorname{Max}$ \\
\hline$\%$ Turnout & -5.24 & 2.59 & -19.48 & 3.17 \\
\hline Registered voters & -34.66 & 41.86 & -143 & 203 \\
\hline \multicolumn{5}{|l|}{ Income distribution indicators } \\
\hline Mean Income (Thousand Euros) & -0.45 & 1.81 & -9.95 & 17.39 \\
\hline Median to Mean Income Ratio & 0.0025 & 0.0323 & -0.1641 & 0.1774 \\
\hline Gini Index & 0.0072 & 0.0227 & -0.0993 & 0.1159 \\
\hline Ratio of percentiles: p80/p20 & 0.4060 & 0.9963 & -1.7019 & 10.7054 \\
\hline 20th percentile, p20 & -0.6577 & 1.1658 & -6.3602 & 2.2815 \\
\hline$\%$ foreign people (all) & 4.71 & 2.92 & -1.98 & 16.23 \\
\hline$\%$ immigrants from Asia and Africa & 1.98 & 2.15 & -9.97 & 10.99 \\
\hline$\%$ immigrants from East Europe & 2.33 & 1.57 & -3.04 & 7.89 \\
\hline$\%$ single aged $<64$ & 3.05 & 2.18 & -6.00 & 15.29 \\
\hline population density^ & -0.0397 & 0.8347 & -3.8853 & 7.5949 \\
\hline$\%$ female & -0.50 & 1.46 & -5.81 & 5.58 \\
\hline average age & -0.09 & 1.44 & -6.02 & 4.85 \\
\hline$\%$ homeowners & -3.58 & 4.79 & -26.9 & 35.81 \\
\hline population & 0.80 & 55.20 & -192 & 253 \\
\hline Number of obs. (precincts) & 434 & & & \\
\hline population in thousands $/ \mathrm{km}^{2}$ & & & & \\
\hline
\end{tabular}


Table 2. Turnout and income inequality indicators

\begin{tabular}{|c|c|c|c|}
\hline & \multicolumn{3}{|c|}{ OLS regressions } \\
\hline \multirow[t]{2}{*}{ year 2009} & $-5.06^{* * *}$ & $-4.44^{* * *}$ & $-4.31^{* * *}$ \\
\hline & $(0.35)$ & $(0.34)$ & $(0.35)$ \\
\hline \multirow[t]{2}{*}{ Mean income } & $0.68^{* * *}$ & $0.61^{* * *}$ & $0.32^{* * *}$ \\
\hline & $(0.09)$ & $(0.06)$ & $(0.06)$ \\
\hline \multirow[t]{2}{*}{ Median to Mean Income Ratio } & $49.45^{* * *}$ & & \\
\hline & $(5.82)$ & & \\
\hline \multirow[t]{2}{*}{ Gini Index } & & $-73.14^{* * *}$ & \\
\hline & & $(6.96)$ & \\
\hline \multirow[t]{2}{*}{ p80/p20 } & & & $-1.95^{* * *}$ \\
\hline & & & $(0.33)$ \\
\hline \multirow[t]{2}{*}{ Constant } & $24.09 *$ & $98.37^{* * *}$ & $81.35^{* * *}$ \\
\hline & $(6.85)$ & $(1.69)$ & $(0.65)$ \\
\hline R-squared & 0.30 & 0.34 & 0.28 \\
\hline Obs & 868 & 868 & 868 \\
\hline \multicolumn{4}{|l|}{ Robust S.E. in brackets. } \\
\hline \multicolumn{4}{|l|}{${ }^{*} \mathrm{p}<0.10,{ }^{* *} \mathrm{p}<0.05,{ }^{* * *} \mathrm{p}<0.01$} \\
\hline
\end{tabular}


Table 3a. Turnout, ratio Median/Mean and ethnic heterogeneity

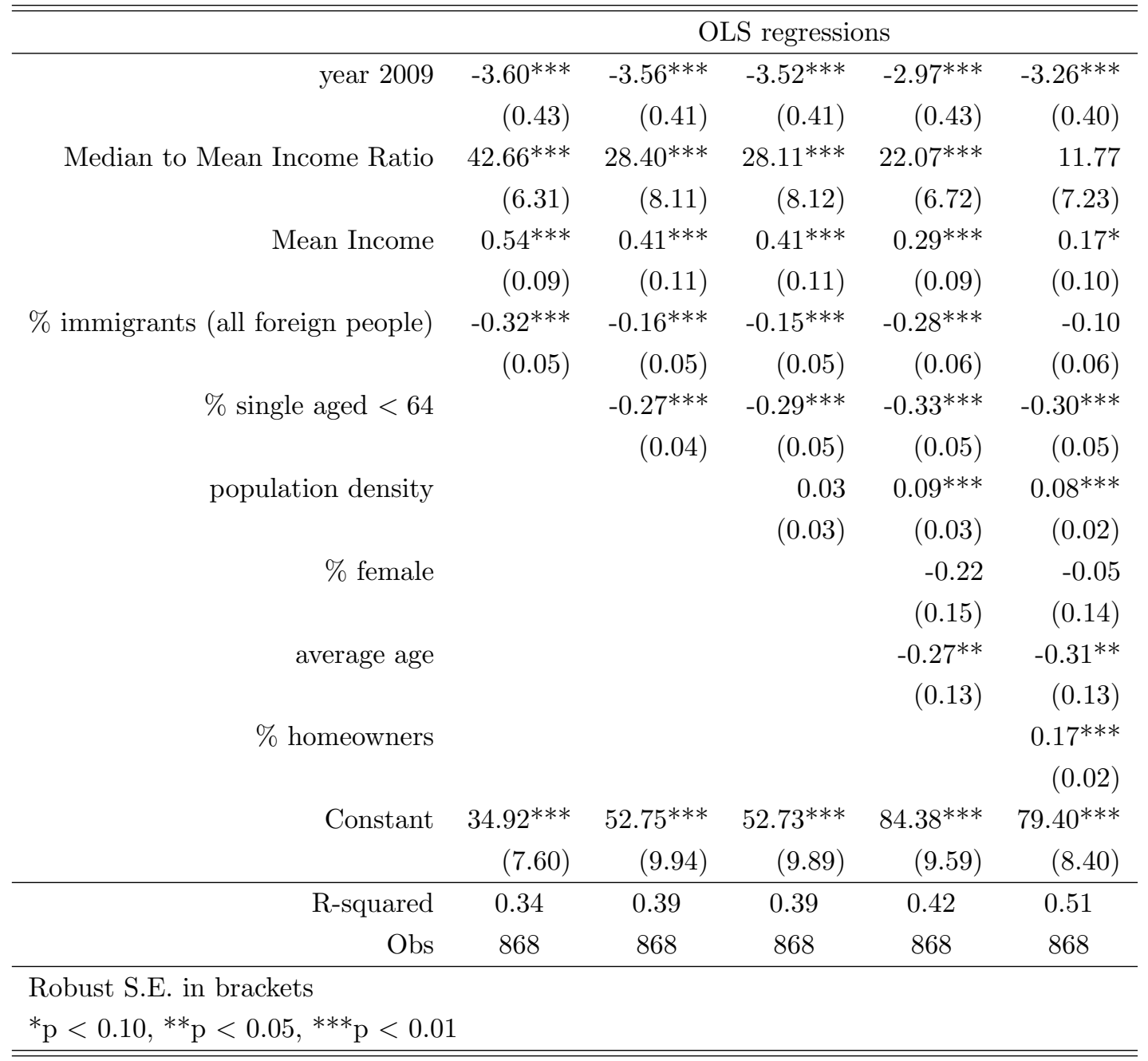


Table 3b. Turnout, Gini Index and ethnic heterogeneity

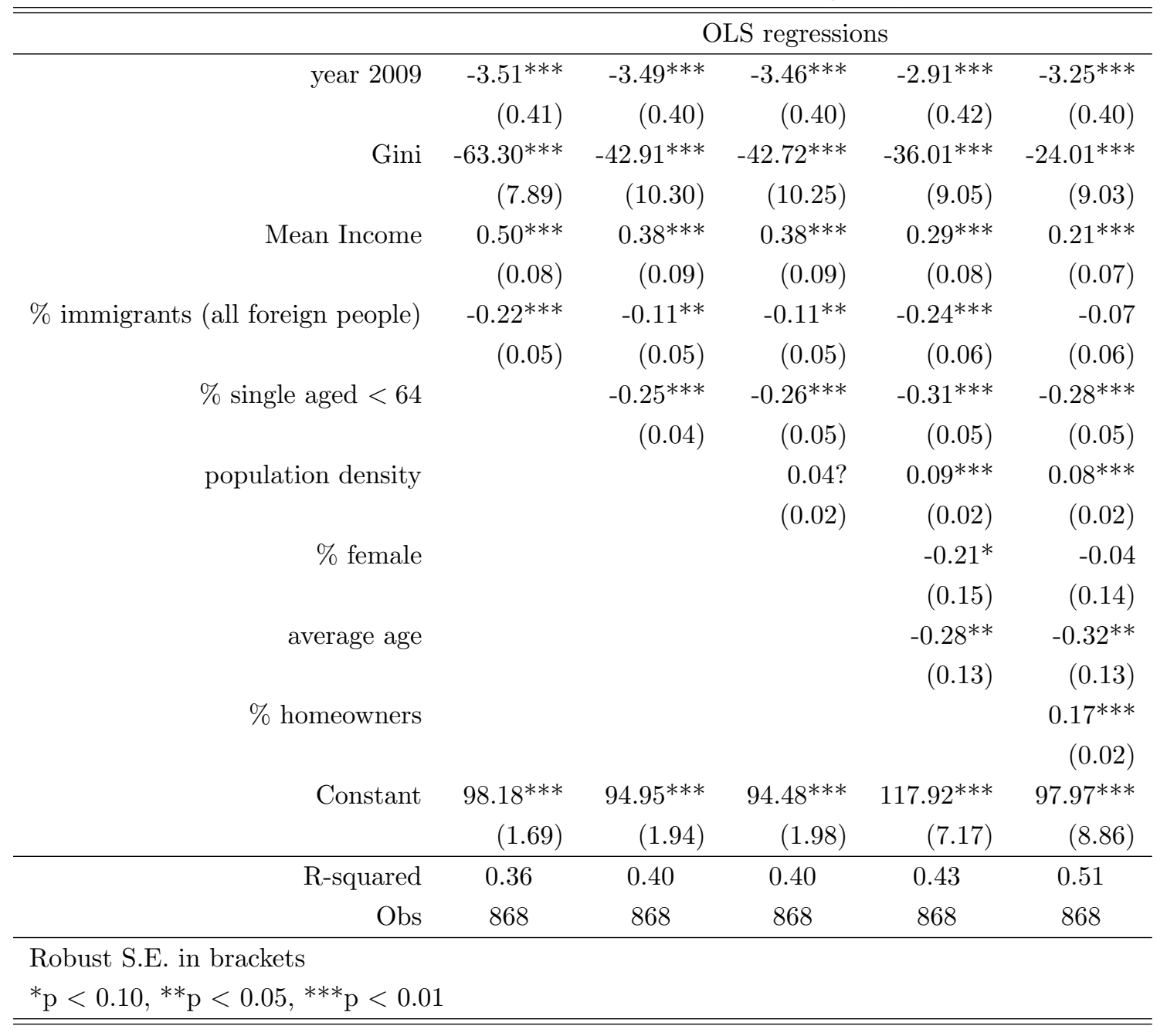


Table 3c. Turnout, Ratio 80th/20th percentiles and ethnic heterogeneity

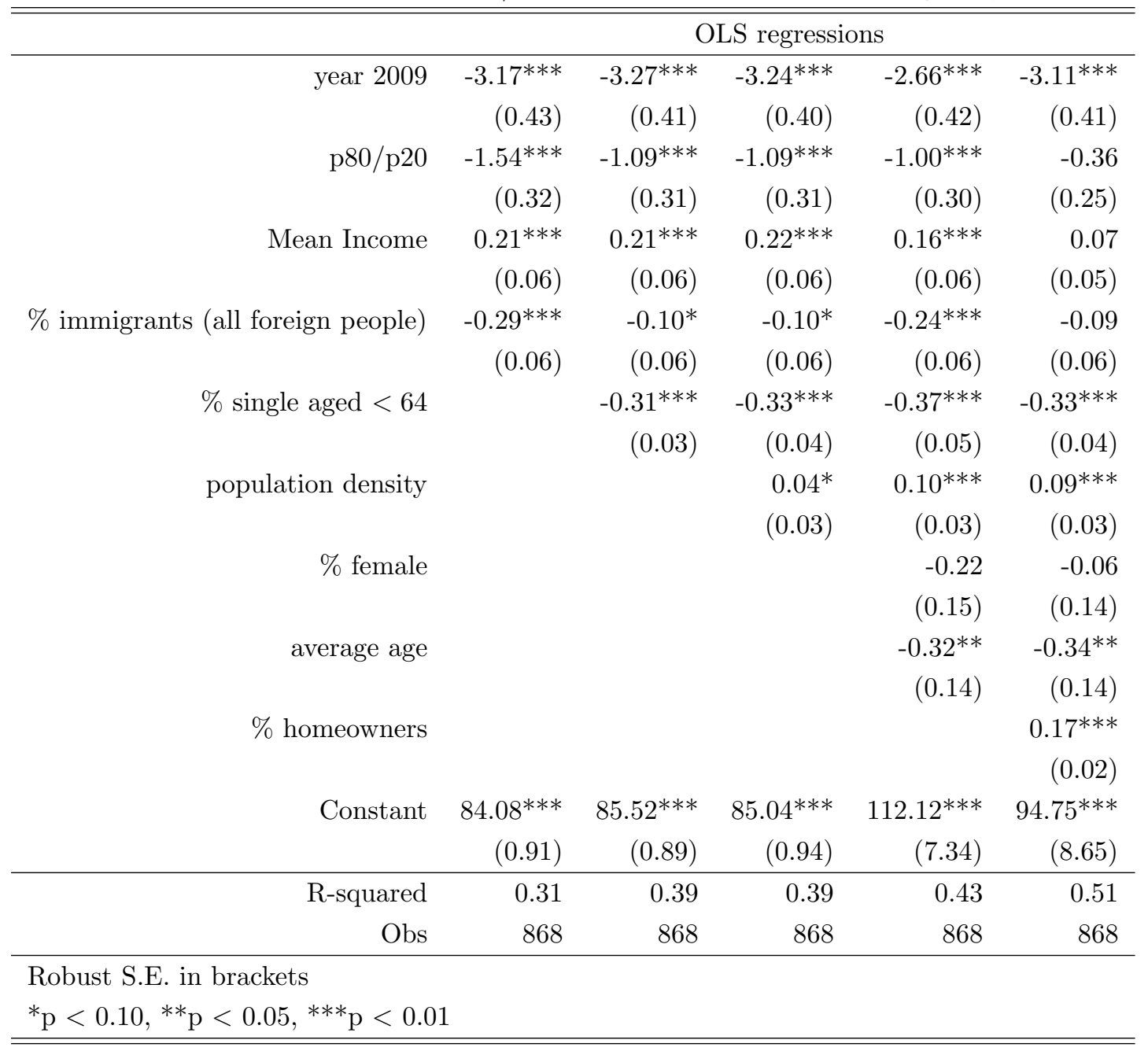


Table 4a. Turnout, ratio Median/Mean and ethnic heterogeneity

\begin{tabular}{|c|c|c|c|c|c|}
\hline \multirow[b]{2}{*}{ year 2009} & \multicolumn{5}{|c|}{ FE regressions } \\
\hline & $-4.41^{* * *}$ & $-4.15^{* * *}$ & $-4.29 * * *$ & $-4.11^{* * *}$ & $-4.11^{* * *}$ \\
\hline & $(0.24)$ & $(0.29)$ & $(0.28)$ & $(0.30)$ & $(0.32)$ \\
\hline \multirow[t]{2}{*}{ Median to Mean Income Ratio } & $9.56^{*}$ & 8.45 & 8.53 & 7.81 & 7.81 \\
\hline & $(5.16)$ & $(5.31)$ & $(5.26)$ & $(5.34)$ & $(5.39)$ \\
\hline \multirow[t]{2}{*}{ Mean Income } & $0.32^{* * *}$ & $0.30^{* * *}$ & $0.29^{* * *}$ & $0.28^{* * *}$ & $0.28^{* * *}$ \\
\hline & $(0.10)$ & $(0.10)$ & $(0.10)$ & $(0.10)$ & $(0.10)$ \\
\hline \multirow[t]{4}{*}{ \% immigrants (all foreign people) } & $-0.15^{* * *}$ & $-0.14^{* * *}$ & $-0.11^{* *}$ & $-0.11^{* *}$ & $-0.11^{* *}$ \\
\hline & $(0.04)$ & $(0.04)$ & $(0.05)$ & $(0.05)$ & $(0.05)$ \\
\hline & & $-0.11^{*}$ & $-0.12^{*}$ & $-0.14^{* *}$ & $-0.14^{* *}$ \\
\hline & & $(0.07)$ & $(0.07)$ & $(0.06)$ & $(0.07)$ \\
\hline \multirow[t]{2}{*}{ population density } & & & $-0.33^{*}$ & $-0.35^{*}$ & $-0.35^{*}$ \\
\hline & & & $(0.20)$ & $(0.20)$ & $(0.20)$ \\
\hline \multirow[t]{2}{*}{$\%$ female } & & & & $0.17^{*}$ & $0.17^{*}$ \\
\hline & & & & $(0.10)$ & $(0.10)$ \\
\hline \multirow[t]{2}{*}{ average age } & & & & -0.17 & -0.17 \\
\hline & & & & $(0.11)$ & $(0.11)$ \\
\hline \multirow[t]{2}{*}{$\%$ homeowners } & & & & & -0.00 \\
\hline & & & & & $(0.04)$ \\
\hline \multirow[t]{2}{*}{ Constant } & $66.61^{* * *}$ & $69.36^{* * *}$ & $73.10^{* * *}$ & $74.60^{* * *}$ & $74.64^{* * *}$ \\
\hline & $(6.23)$ & $(6.71)$ & $(7.22)$ & $(10.28)$ & $(10.41)$ \\
\hline Number of groups & 434 & & & & \\
\hline Obs & 868 & & & & \\
\hline \multicolumn{6}{|l|}{ Robust S.E. in brackets } \\
\hline${ }^{*} \mathrm{p}<0.10,{ }^{* *} \mathrm{p}<0.05, * * * \mathrm{p}<0.0$ & & & & & \\
\hline
\end{tabular}


Table 4b. Turnout, Gini Index, ethnic heterogeneity and controls

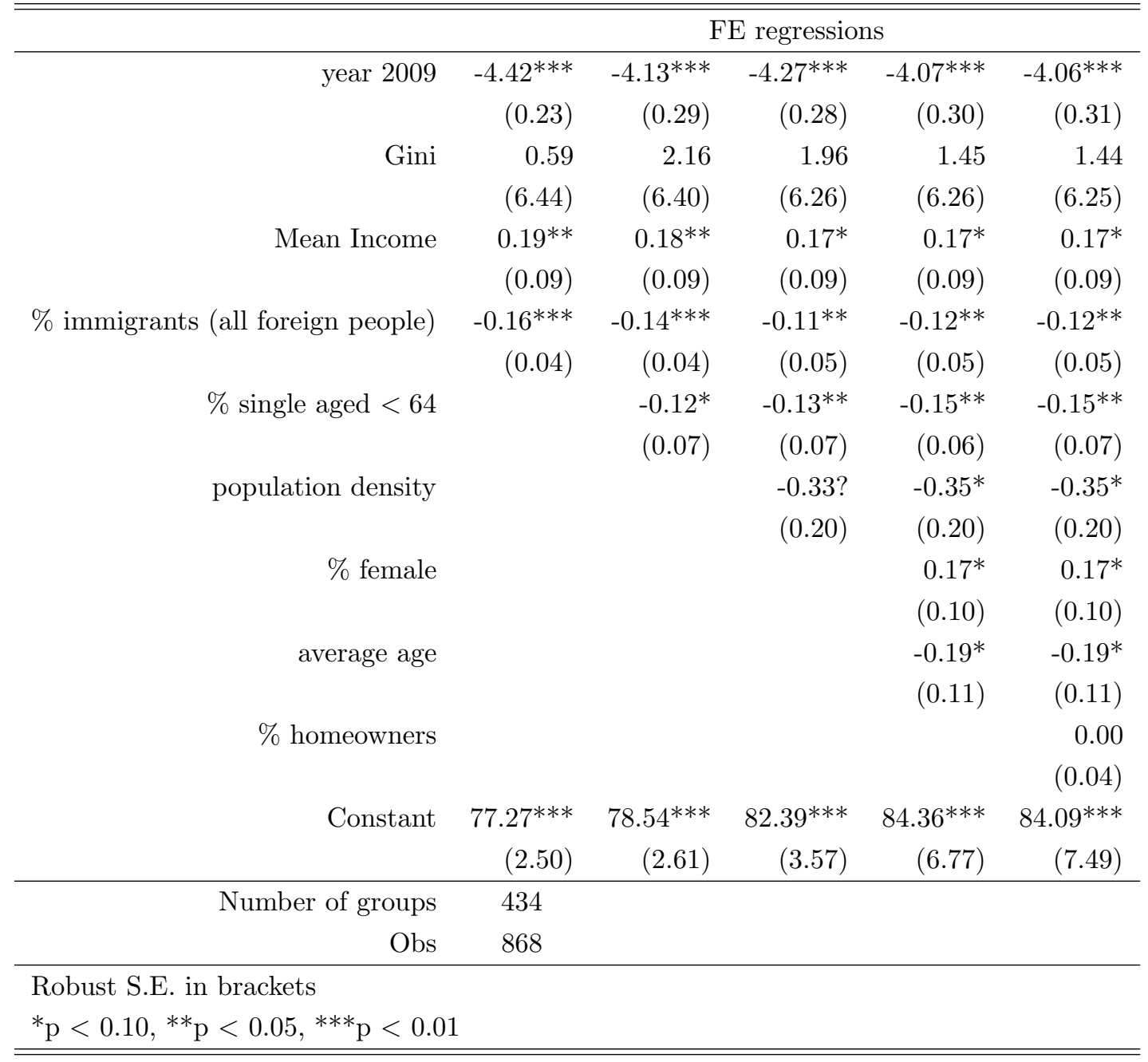


Table 4c. Turnout, Ratio of percentiles 80th/20th and ethnic heterogeneity

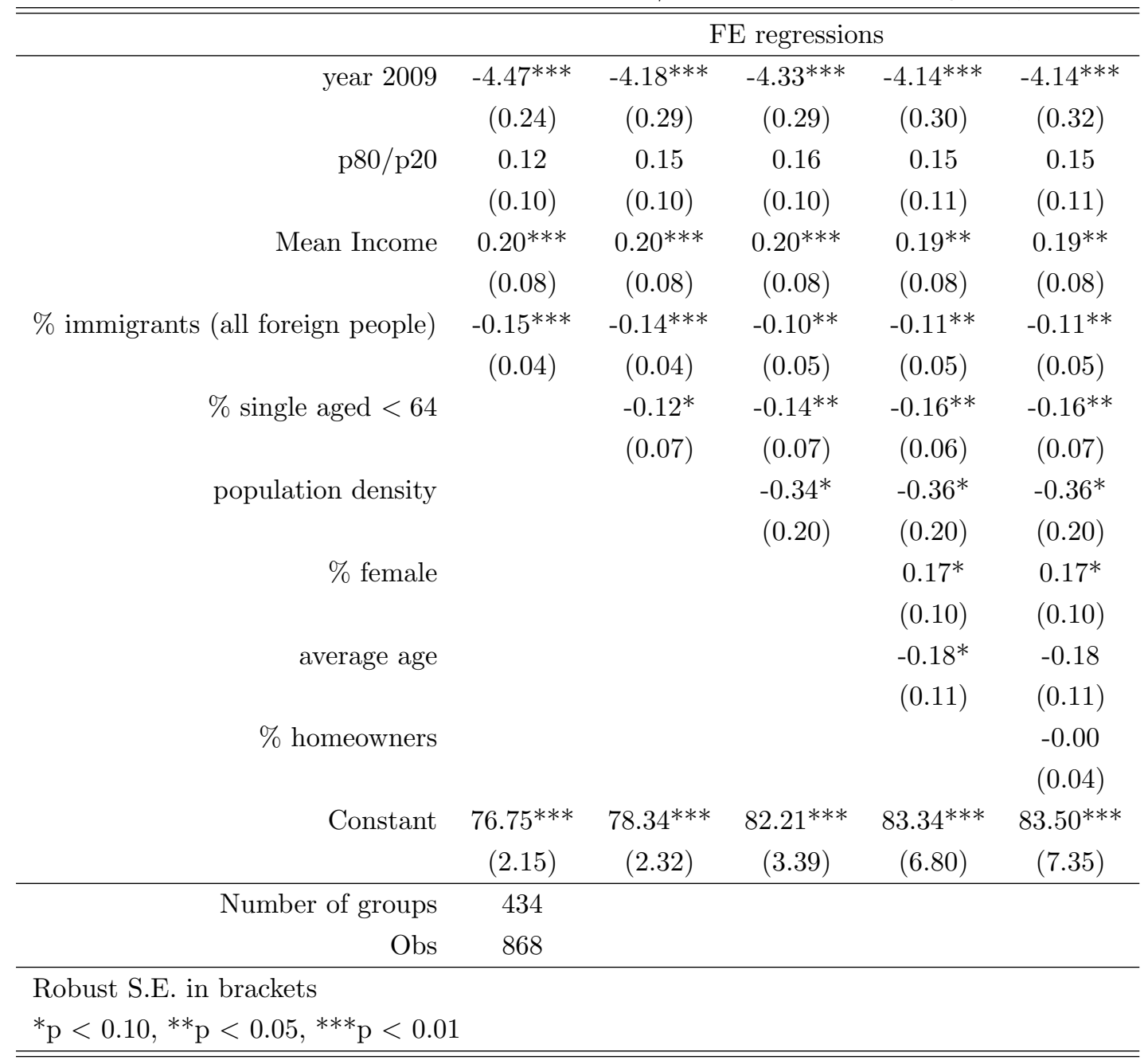


Table 5a. Turnout and ethnic heterogeneity: immigrants from Africa and Asia

\begin{tabular}{|c|c|c|c|c|c|c|}
\hline & OLS & $\mathrm{FE}$ & OLS & $\mathrm{FE}$ & OLS & $\mathrm{FE}$ \\
\hline year 2009 & $-4.01 * * *$ & $-4.76^{* * *}$ & $-3.39 * * *$ & $-4.30 * * *$ & $-3.37 * * *$ & $-4.28^{* * *}$ \\
\hline & $(0.36)$ & $(0.17)$ & $(0.37)$ & $(0.26)$ & $(0.34)$ & $(0.28)$ \\
\hline Gini & $-65.50 * * *$ & -0.40 & $-36.48^{* * *}$ & 1.27 & $-23.91 * * *$ & 1.27 \\
\hline & $(7.50)$ & $(6.38)$ & $(9.06)$ & $(6.19)$ & $(9.03)$ & $(6.19)$ \\
\hline Mean Income & $0.52^{* * *}$ & $0.21^{* *}$ & $0.30 * * *$ & $0.19^{* *}$ & $0.21^{* * *}$ & $0.19^{* *}$ \\
\hline & $(0.07)$ & $(0.09)$ & $(0.08)$ & $(0.09)$ & $(0.07)$ & $(0.09)$ \\
\hline \multirow[t]{2}{*}{$\%$ immigrants (Africa and Asia) } & $-0.26^{* * *}$ & $-0.20 * * *$ & $-0.30^{* * *}$ & $-0.15^{* *}$ & -0.11 & $-0.15^{* *}$ \\
\hline & $(0.06)$ & $(0.07)$ & $(0.07)$ & $(0.07)$ & $(0.07)$ & $(0.07)$ \\
\hline \multirow[t]{2}{*}{$\%$ single aged $<64$} & & & $-0.32^{* * *}$ & $-0.17 * * *$ & $-0.28 * * *$ & $-0.17^{* * *}$ \\
\hline & & & $(0.05)$ & $(0.06)$ & $(0.05)$ & $(0.06)$ \\
\hline \multirow[t]{2}{*}{ population density } & & & $0.10^{* * *}$ & $-0.37^{*}$ & $0.08^{* * *}$ & $-0.36^{*}$ \\
\hline & & & $(0.02)$ & $(0.20)$ & $(0.02)$ & $(0.2)$ \\
\hline \multirow[t]{2}{*}{$\%$ female } & & & -0.21 & 0.16 & -0.05 & 0.16 \\
\hline & & & $(0.15)$ & $(0.10)$ & $(0.14)$ & $(0.1)$ \\
\hline \multirow[t]{2}{*}{ average age } & & & $-0.27^{* *}$ & -0.16 & $-0.32^{* *}$ & -0.16 \\
\hline & & & $(0.13)$ & $(0.10)$ & $(0.13)$ & $(0.11)$ \\
\hline \multirow[t]{2}{*}{$\%$ homeowners } & & & & & $0.16^{* * *}$ & 0.01 \\
\hline & & & & & $(0.02)$ & $(0.04)$ \\
\hline \multirow[t]{2}{*}{ Constant } & $98.27^{* * *}$ & $76.93^{* * *}$ & $117.58^{* * *}$ & $83.37^{* * *}$ & $98.30^{* * *}$ & $82.72^{* * *}$ \\
\hline & $(1.69)$ & $(2.50)$ & $(7.24)$ & $(6.67)$ & $(8.87)$ & $(7.37)$ \\
\hline Number of groups & 434 & & & & & \\
\hline Obs & 868 & & & & & \\
\hline
\end{tabular}

Robust S.E. in brackets

${ }^{*} \mathrm{p}<0.10,{ }^{*} \mathrm{p}<0.05, * * * \mathrm{p}<0.01$ 
Table 5b. Turnout and ethnic heterogeneity: immigrants from East Europe

\begin{tabular}{|c|c|c|c|c|c|c|}
\hline & OLS & $\mathrm{FE}$ & OLS & $\mathrm{FE}$ & OLS & $\mathrm{FE}$ \\
\hline year 2009 & $-3.89 * * *$ & $-4.76^{* * *}$ & $-3.36^{* * *}$ & $-4.41^{* * *}$ & $-3.43^{* * *}$ & $-4.38^{* * *}$ \\
\hline & $(0.45)$ & $(0.20)$ & $(0.45)$ & $(0.27)$ & $(0.40)$ & $(0.28)$ \\
\hline Gini & $-70.86^{* * *}$ & -2.88 & $-41.14^{* * *}$ & -0.75 & $-25.15^{* * *}$ & -0.71 \\
\hline & $(7.23)$ & $(6.27)$ & $(9.02)$ & $(6.20)$ & $(9.23)$ & $(6.20)$ \\
\hline Mean Income & $0.57^{* * *}$ & $0.24^{* * *}$ & $0.37^{* * *}$ & $0.21^{* *}$ & $0.23^{* * *}$ & $0.21^{* *}$ \\
\hline & $(0.07)$ & $(0.09)$ & $(0.08)$ & $(0.09)$ & $(0.08)$ & $(0.09)$ \\
\hline \multirow[t]{2}{*}{ \% immigrants (East Europe) } & $-0.25^{* *}$ & $-0.15^{* *}$ & $-0.21^{* *}$ & -0.08 & -0.03 & -0.07 \\
\hline & $(0.11)$ & $(0.07)$ & $(0.10)$ & $(0.07)$ & $(0.09)$ & $(0.07)$ \\
\hline \multirow[t]{2}{*}{$\%$ single aged $<64$} & & & $-0.34 * * *$ & $-0.16^{* *}$ & $-0.29 * * *$ & $-0.16^{* *}$ \\
\hline & & & $(0.05)$ & $(0.06)$ & $(0.05)$ & $(0.06)$ \\
\hline \multirow[t]{2}{*}{ population density } & & & $0.09 * * *$ & $-0.43^{* *}$ & $0.08^{* * *}$ & $-0.41^{* *}$ \\
\hline & & & $(0.03)$ & $(0.20)$ & $(0.02)$ & $(0.19)$ \\
\hline \multirow[t]{2}{*}{$\%$ female } & & & -0.16 & $0.20 *$ & -0.02 & $0.19^{*}$ \\
\hline & & & $(0.14)$ & $(0.10)$ & $(0.14)$ & $(0.10)$ \\
\hline \multirow[t]{2}{*}{ average age } & & & $-0.23^{*}$ & -0.13 & $-0.30 * *$ & -0.12 \\
\hline & & & $(0.13)$ & $(0.11)$ & $(0.13)$ & $(0.11)$ \\
\hline \multirow[t]{2}{*}{$\%$ homeowners } & & & & & $0.17^{* * *}$ & 0.01 \\
\hline & & & & & $(0.02)$ & $(0.04)$ \\
\hline \multirow[t]{2}{*}{ Constant } & $98.63^{* * *}$ & $76.96^{* * *}$ & $113.02^{* * *}$ & $80.50 * * *$ & $95.83^{* * *}$ & $79.27^{* * *}$ \\
\hline & $(1.67)$ & $(2.50)$ & $(6.71)$ & $(6.58)$ & $(7.98)$ & $(7.34)$ \\
\hline Number of groups & 434 & & & & & \\
\hline Obs & 868 & & & & & \\
\hline \multicolumn{7}{|l|}{ Robust S.E. in brackets } \\
\hline${ }^{*} \mathrm{p}<0.10,{ }^{* *} \mathrm{p}<0.05, * * * \mathrm{p}$ & 0.01 & & & & & \\
\hline
\end{tabular}

